\title{
GIS ANALYSIS OF PHYSICAL ACCESSIBILITY TO FOOD MARKETS IN THARAKA REGION OF KENYA
}

\author{
Dickson Kinoti KIBETU * ${ }^{1}$, Julius Mburu HUHO ${ }^{2}$, Tom Odhiambo OUNA ${ }^{1}$
}

\author{
Address: \\ ${ }^{1}$ Karatina University,Department of Humanities, P.O Box 1975, Karatina, Kenya. \\ ${ }^{2}$ Garissa University, Department of Geography, P. O. Box 1801, 70100, Garissa, Kenya. \\ * Corresponding author: kinotikibetu@gmail.com
}

\begin{abstract}
In semi-arid rural Kenya, most households travel long distances to access food markets. This has negative effects on food consumption and the use of market facilities. Over70 \% of farmers in Tharaka Constituency lack access to formal markets often relying on contracted middlemen who buy at farm gate for traders in major urban centres. Studies on intravariation in accessibility to market services remains scanty, yet market purchases account for most food consumed across urban and rural areas. Distance defines accessibility and performance of market facilities in most areas where food insecurity and malnutrition are common. This study used Geographic Information Systems (GIS) to measure physical accessibility to open air markets within semi-arid Tharaka, a constituency where vulnerability to acute food shortage is comparatively high. Normative, administrative and geospatial datasets were used in the analysis. Results showed that geographic accessibility to local market centres vary spatially across the villages. In terms of market accessibility, $40.4 \%$ of the total population live in areas with high inaccessibility risks while $36.1 \%$ are found in places with low inaccessibility risks and only $23.5 \%$ of the population exists in areas with moderate inaccessibility risks. This means a large proportion of deprived population live in villages within high to very high inaccessibility risk areas. This spatial inequity has implications on household food security and explains the chronic problems of hunger and malnutrition experienced in the area. Therefore, markets within high inaccessibility risk areas should be upgraded and infrastructure thereof improved to enable food mobility across these areas.
\end{abstract}

Keywords: Geographic accessibility; open air markets; food security; GIS JEL: R52, R58, H41

\section{INTRODUCTION}

Population growth and inability of people to produce their own food has increased demand for food worldwide. As a result, more people are now buying food supplies from local markets which are spatially disperse and temporal especially in developing countries. Therefore, availability and accessibility to market facilities is important in averting food insecurity and addressing problems of malnutrition in developing countries. Although wellfunctioning market systems promotes food trade and ensures consistent supply, poor geographic access to food retail markets remains a big challenge. In Sub Saharan Africa alone, close to $60 \%$ of the households own less than one hectare of farmland comprising a large proportion of all small scale farmers in the world (Eyzaguirre et al., 2006). Most of these farmers produce traditional food crops which are sold in the informal and village markets thus fetching low incomes to farmers. Although there is a consensus on market participation as an important pathway for enhancing food security and general improvement in the livelihood of small scale farmers, the participation rate of smallholder farmers in marketization is low and often hindered by high transaction costs due to small surplus production (Torero, 2011). The greatest challenge facing development of small scale farming is availability of markets and issues to do with market accessibility.

In Kenya, market access and efficient distribution of food from areas with excess production to those in need is limited by poor road infrastructure (RSA, 2015). This translates to many households being cut off from available food supplies while consumers end up paying up for high food prices in local markets. Notably, in the rural and remote semi-arid areas, farmers face constraints of physical accessibility to market facilities due to long distances they have to trek to nearest village markets. As a result, most of them miss out the opportunities to commercialise their produce and increase a share of market sales or still diversify their market products (Asfaw et al., 2010). This influences farmers' as well as households' decision to use markets and also the quantity of produce to sell or buy (Omiti et al., 2009; Makhura, 2001). Physical accessibility is an important factor in the use of markets more so in rural areas where long distances to markets impact on the ability to access markets for food needs, purchase of merchandise and livestock sales for financial resources. One of the objectives of Kenya's food and nutrition security policy 2011 is to increase the quantity and quality of food available, accessible and affordable to all at all times (GOK, 2011). Approaches identified by the policy to realise this are those geared towards increasing production, maintenance of strategic 
food reserves and reduction of post-harvest losses without underscoring the significant role markets can play in promoting food availability and access within local areas.

An important question on which strategies can be adopted for farming to support small scale households with adequate income and food rations is of essence in the wake of increased poverty and uneconomical subdivisions of small scale lands. The fact that in rural areas most people are net buyers of food makes the situation more complicated as echoed in studies done locally (Waithaka et al., 2006; Jayne et al., 2016). Generally, these studies have shown how small scale mixed livestock and crop farmers face challenges in satisfying income and meeting food needs.

Although improving local food distribution systems and physical accessibility to markets can address challenges of food availability, it has not received much attention in policy and research. This clearly calls for shift of focus from increase production strategies of addressing food insecurity in the country to those of enhancing marketization and distribution of local produce. Improving physical accessibility to markets promotes linkage between consumers and producers opening up more opportunities for commercialisation and consumption of local produce. In the country, poor physical accessibility limits efficient food distribution and market access leading to high food prices for consumers and low food supplies in local markets by farmers. Given this scenario, present study seeks to model physical accessibility to open food markets using geographic information systems and analyse how inaccessibility impacts on household food security. Geographic information systems has been applied in measurement for physical accessibility of retail sites, health care planning, transport as well as emergency services (Bhatti, 2005; Noor et al., 2006; Smoyer et al., 2004). However, a review of literature on GIS based measures of access shows that its application has been extensively in the health sector. There is limited work on the use of GIS outside the domain of health care as large part of existing literature is on use of GIS to examine spatial patterns of disease spread and partly in environmental studies for correlation analysis.

This research is a first attempt to show how spatial accessibility to food retail markets can be measured using GIS to assist understand local area food needs and for planning of food and nutrition security interventions for deprived population. This is important in realising sustainable development goals number 2, 3 and 12 at both local and national levels.

\section{Rationale of the Study}

This paper seeks to analyse the problem of geographic accessibility to rural village food markets by households. Village food markets are centers in rural areas where local farmers sell their food crops and livestock. These markets operate periodically at certain days of the week. Measuring physical accessibility is important in understanding service utility of markets because number of people using any given facility will normally decrease as the distance from that facility increase. Due to under developed transport networks in most rural areas, mobility is challenging especially moving of farm produce to the open air markets.

In the rural areas, majority of people access food through open air markets and as such physical accessibility defines food security especially for the resource poor households who depend on markets for food. In modelling physical accessibility, administrative, normative and geospatial data was acquired and used (Table 1).

Table 1: Data used in modelling physical accessibility

\begin{tabular}{|c|c|c|}
\hline Type of data & Data sets name & $\begin{array}{l}\text { Indicator } \\
\text { measured }\end{array}$ \\
\hline Geospatial & Open air markets & $\begin{array}{l}\text { Location } \\
\text { position of } \\
\text { markets }\end{array}$ \\
\hline Administrative & $\begin{array}{l}\text { Villages, sub } \\
\text { locations }\end{array}$ & $\begin{array}{l}\text { Market service } \\
\text { range area }\end{array}$ \\
\hline $\begin{array}{l}\text { Socio- } \\
\text { economic }\end{array}$ & Population & $\begin{array}{l}\text { Number of } \\
\text { Deprived } \\
\text { persons }\end{array}$ \\
\hline Normative & $\begin{array}{l}\text { Road classes and } \\
\text { associated speed } \\
\text { limits }\end{array}$ & $\begin{array}{l}\text { Travel time to } \\
\text { nearest market }\end{array}$ \\
\hline
\end{tabular}

Location position of open air markets was captured to show spatial distribution of market facilities and to aid in computing distances across market facilities. Villages and sub location geometry data was applied to define catchment areas for markets since they comprise source regions of households using these markets. Population data was needed to understand socio-economic characteristics of market dependent households who represented deprived persons in need of food. In measuring mobility, important road network data was the road class and associated speed limits to be used to compute travel time from villages to the markets.

\section{DATA AND METHODS}

\section{Study Area}

Tharaka constituency is one of the three constituencies within Tharaka Nithi County. It lies between sub-humid highlands to the west and the arid and semi-arid plains to the south and east (Figure 1). The constituency has a total population of 130,098 persons and 27493 households spread across five wards. These wards include; Nkondi, Mukothima, Marimanti, Gatunga and Chiakariga. Population distribution across the study area vary spatially with Chiakariga ward having a population of 34,679 ; Marimanti ward with 32,609, Gatunga ward with 21,421 while Nkondi has 15,574 and finally Mukothima ward has approximately 28,555 persons (KNBS, 2009). Agriculture is the main livelihood of the Tharaka sub tribe with at least $92 \%$ of the households engaged in agricultural activities (ISS, 2016). Communities living in this area practice mixed farming and the dominant staple crops grown are maize, bulrush millet, sorghum and legumes (Smucker and Binsey, 2008). The area comprises of low, hilly, stony and sandy lowlands with major economic activities being crop farming and livestock keeping. Based on food security vulnerability analysis, the region is classified into 
marginal mixed farming (MMF), rain-fed cropping (RFC) zone and the mixed farming (MF) zone (WFP, 2006).

\section{Open air markets}

Market centres are important food hubs in the study area as most households sell and even buy from these open air retail village markets. Each of the open air market was visited to understand food marketing systems where the type of food sold, physical infrastructure and functional services performed were examined. Geographic location was mapped by collecting coordinates of the markets using Trimble GPS receiver. To increase positional accuracy, three readings for latitude and longitude were taken and the average reading used to give the final location for that particular market. Field survey revealed that markets in the study area vary in market functional services from those dealing with food bulking services, to livestock auctioning as well as to food assembly and livestock auctioning (Table 1).

Figure 1: Physiographic map of Tharaka constituency showing $5^{\text {th }}$ level Administrative Units

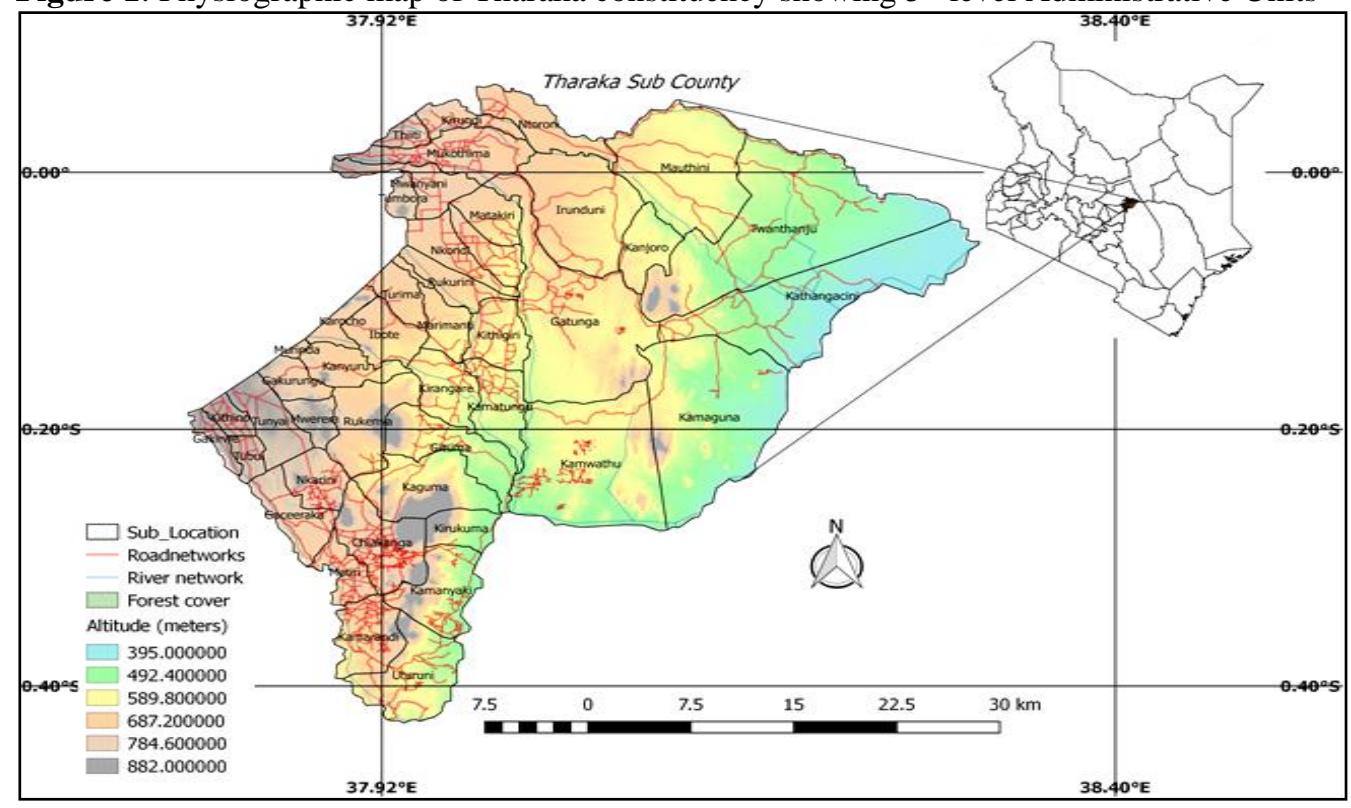

Table 1: Location and functions of village open air market centres

\begin{tabular}{llrr}
\hline Market Name & Function and Service of the Market & Latitude (DD) & Longitude (DD) \\
\hline Mukothima & Food Assembly market & 0.013272 & 37.945258 \\
Miomponi & Food Assembly market & -0.000625 & 37.904954 \\
Nkondi & Food Assembly market & -0.045627 & 37.957797 \\
Gaciongo & Food Assembly market & -0.029883 & 38.019463 \\
Kathangacini & Livestock market & -0.094119 & 38.151877 \\
Gatunga & Food and Livestock market & -0.997253 & 38.010969 \\
Marimanti & Food and Livestock market & -0.157041 & 37.977835 \\
Kibung'a & Food Assembly market & -0.076775 & 37.919951 \\
Tunyai & Food and Livestock market & -0.175883 & 37.836882 \\
Nkarini & Food Assembly market & -0.243508 & 37.877654 \\
Chiakariga & Food and Livestock market & -0.277302 & 37.923869 \\
Shauri & Livestock market & 0.012805 & 38.073438 \\
Karocho & Food Assembly market & -0.131622 & 37.885863 \\
Matiri & Food Assembly market & -0.319019 & 37.901902 \\
\hline
\end{tabular}

\section{Population distribution}

Population data which was projected to 2018 based on 2009 Kenya population and housing census data was sourced from Tharaka Nithi county office of the Central Bureau of Statistics (KNBS, 2009). Sub location was chosen because it forms the lowest and fifth administrative level in Kenya. Currently, census data is aggregated to this level and therefore population data at sub location level forms highest spatial resolution demographic data available for public access. According to the projected 2018 population data, Tharaka constituency has a total population of 147583 inhabitants spatially spread across 48 sub locations.

\section{Administrative units}

Paper map showing Tharaka North and South sub counties was acquired from Tharaka Constituency Office. It was scanned and then digitized in CATALINX digitizing software. All the 48 Sub location boundaries were digitized and corrected for errors through running of polygon closure algorithm to ensure there were no slivers or gaps in resultant polygons. The layer was then exported 
to QGIS open source GIS software where the map was reprojected into the common spatial reference system adopted all geospatial datasets used in this study (Figure 2).

\section{Road networks}

Road network vector format data was derived as paper map data supplied by County Kenya Rural Roads Authority (KeRRA) for Tharaka-Nithi based at Chuka town. The sourced data was not adequate for analysis after comparison with Google Earth imagery since it only covered lower level road classes $\mathrm{P}$ and $\mathrm{N}$. It was therefore updated using Open Street Map data accessed using OSM plugin in QGIS. Additionally, road data from the WRS (2019) was also used to supplement county roads data. Both county roads and WRI roads shape files datasets were integrated to derive the final road distribution network data (Figure 3).

\section{Digital Elevation Model}

Elevation in the area range from the lowest of $395 \mathrm{~m}$ to the highest of $882 \mathrm{~m}$ above sea level (Figure 4). Slope was considered an important parameter affecting travel time to and from markets by households. Area slope was derived from the digital elevation model using slope function in QGIS geo processing tool box and expressed in per cent. The region's slope ranged from $0.6 \%$ (Flat surfaces) to 26 $\%$ (steep surfaces). The digital elevation model used was downloaded from NASA Shuttle Terrain Radar Mission in $30 \mathrm{~m}$ to match grid resolution of other datasets.

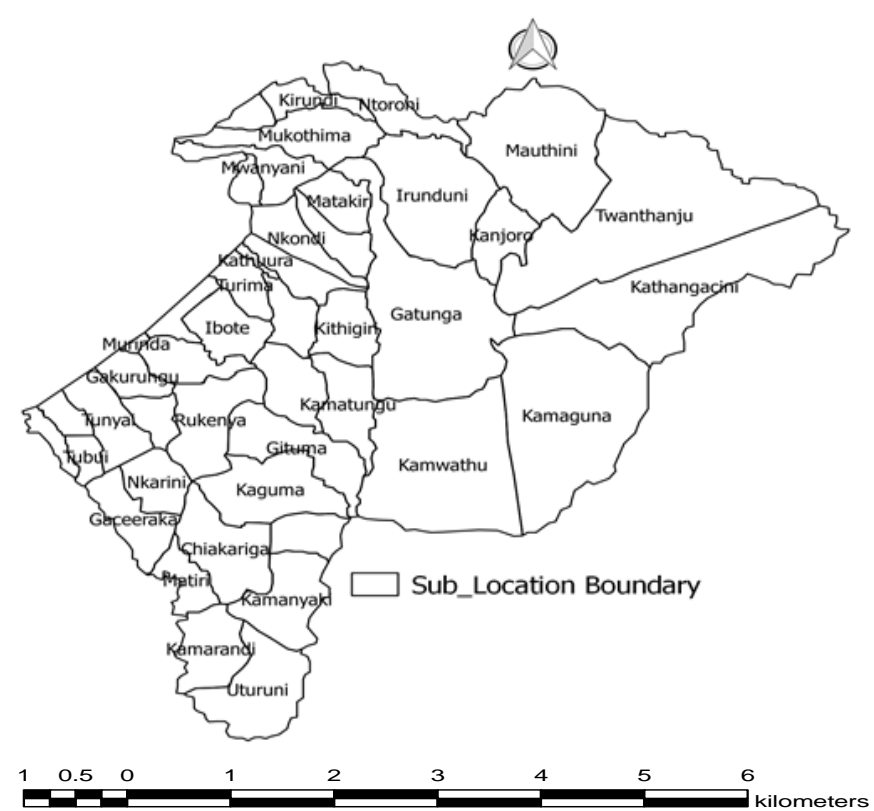

Figure 2: Fifth level administrative units map showing sub location boundaries

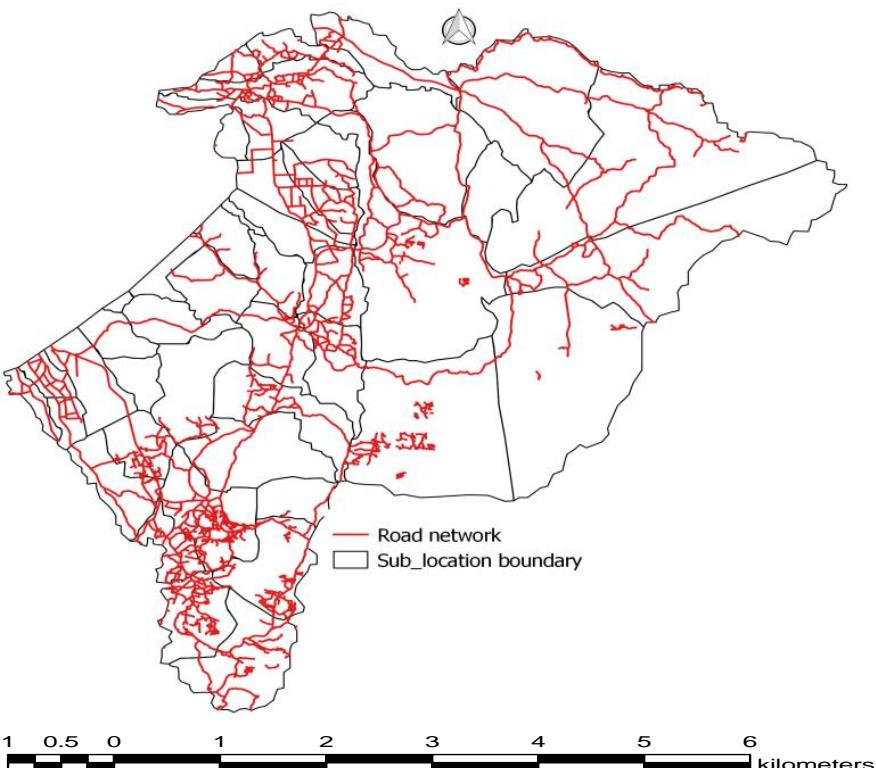

Figure 3: Spatial distribution of roads across the study area 


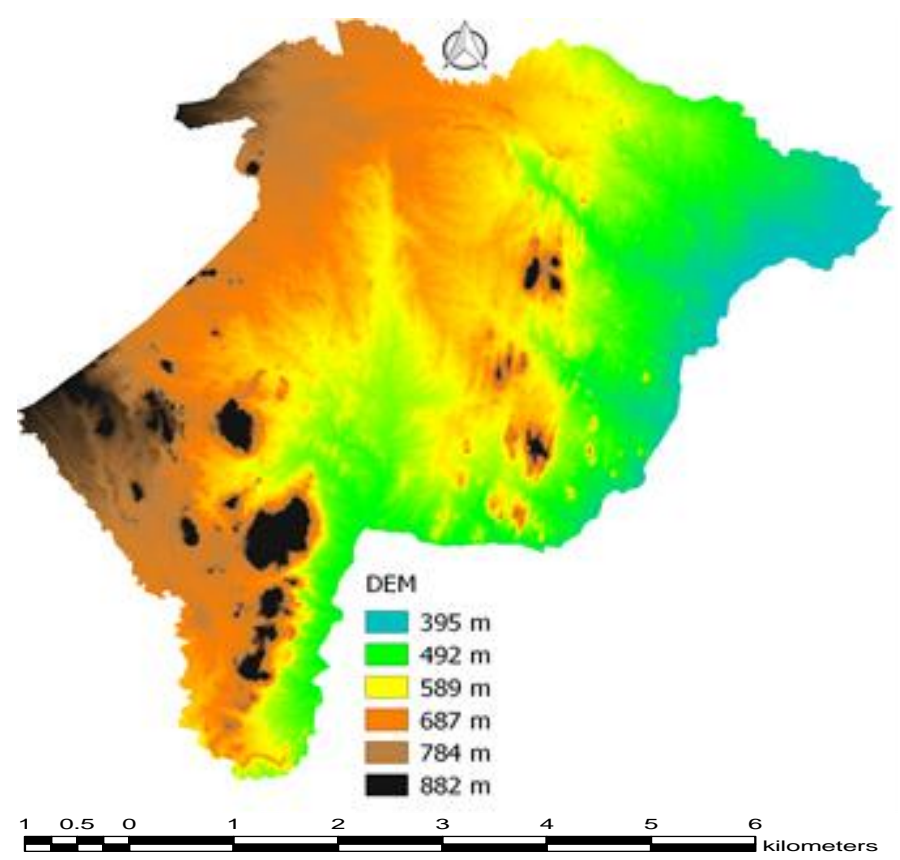

Figure 4: Altitudinal height of the study area in meters

\section{Data Processing Methods}

\section{Creation of sub-location Population Database}

The fifth level administrative units were digitized as polygons and the polygon's centroid calculated to represent a point-polygon feature. Projected population for 2018 for each fifth level administrative unit was then assigned to each centroid. Therefore, a population geo database for all the $48 \mathrm{sub}$ locations was created through linking the administrative units' polygon to sub location population. Resultant database contained relevant data to facilitate GIS analysis and visualisation.

\section{Road Network Classification}

Road distribution map data was cleaned to remove duplicate and short road segments. It was then reclassified based on the Kenya Roads Act, 2015 as primary, secondary and tertiary roads. According to the Act, primary roads are those which connect countries through international boundaries. Secondary roads on the other hand link counties, major towns as well as primary roads. Tertiary roads are those roads that connect small markets and also feed into secondary roads. Tharaka has secondary and tertiary road categories.

\section{Development of Travelling Scenarios}

To understand mobility across markets and villages by households, various transportation modes were considered. Basic transportation modes identified during field survey were walking, cycling and use of vehicles. Identified transportation modes were used in modelling different travelling scenarios. Land use/cover map for the study area was created from recent acquired Landsat 8OLI/TIRS images using semi-automatic classification plugin in QGIS Version 3.8. Four classes of bare land, built up area, thick vegetation and crop land were developed. Speed limits adopted for each land cover were based on recommendations by Nelson (2000); Ray and Ebener (2008). Recommended speed limit assumes travelling surface is always a zero degree slope flat surface. To address this limitation, speed limit correction based on digital elevation model was done to cater for slope variations in the study area. Walking speed was corrected based on Tobler's formula (Tobler, 1993) (Eq.1)

$W=6 \exp \{-3.5 * a b s(S+0.05)\}$

Where:

$W$ is corrected walking velocity in kilometres per hour and $S$ is slope in degrees. Tobler's formula was chosen because it increases or decreases the effective walking speed based on the steepness of surface slope. Corrected walking speed based on slope intensity is as shown in Table 2.

Table2. Walking speed corrected based on slope intensity

\begin{tabular}{lr}
\hline Land Cover & Walking speed $(\mathrm{Km} / \mathrm{hr})$ \\
\hline Bare land & 2.2 \\
Crop land & 1.6 \\
Built up area & 3.1 \\
Thick Vegetation & 1.0 \\
\hline
\end{tabular}

As for road based velocity, slope correction was not done given the flat nature of landscape in the study area. In most cases it is the acceleration which propels the speed of movement; therefore, slope does not influence the overall speed of motorized transportation (motorcycles and vehicles). Speed limits used were those adopted from Ouko et al. (2019) (Table 3). These speed limits were applied because they represent optimal velocities allowable in event of encountered barriers to movement.

Table3. Optimal speed limits for motorised transportation Road Category Motorcycle(Km/hr) Vehicle(Km/hr)

\begin{tabular}{lll}
\hline Primary & 28 & 60 \\
Secondary & 24 & 50 \\
Tertiary & 10 & 30 \\
\hline
\end{tabular}

Note: Based on Ouko et al., 2019 


\section{Data Analysis Techniques}

All datasets were projected to local datum of arc1960 and UTM zone 37 South for purposes of ensuring they were in the same spatial reference properties.

\section{Distance Analysis}

Distance to the nearest market was computed for all the open air markets using Distance to the Nearest Hub tool in QGIS. This tool was used to calculate linear distances covered by the people to the markets moving on foot where there are no roads (Figure 5). Each centroid was assigned the number of villages in each sub location. Calculated distance in kilometres was then classified into a six-point equal interval distance scale starting from the nearest to the farthest as; $0.5-2.4 \mathrm{~km}, 2.4-4.2 \mathrm{~km}, 4.2$ $6.1 \mathrm{~km}, 6.1-8.0 \mathrm{~km}, 8.0-9.8 \mathrm{~km}$ and $9.8-11.7 \mathrm{~km}$.

\section{Travel Time Estimation}

Travel Time was calculated based on a formula by Kayode and Efosa (2014). Average and maximum travel time was computed for walking, motorcycle and vehicular mobility (Table 5). In computing travel time by pedestrians, distances derived through estimation of linear trajectories to the closest road and slope corrected walking velocity were used. Travel time for motorised movement was calculated for secondary and tertiary roads as they were suitable for motorised transport. To get travel duration for vehicles and motor cycles, length of the closest road to each market centre was divided by the optimal speed of $50 \mathrm{~km} / \mathrm{hr}$ adopted for all roads used by vehicles. On the other hand, for motor cycles average speed of $24 \mathrm{~km} / \mathrm{hr}$ was applied assuming barriers encountered by motorcycle users to the markets were the same across all the sub locations.

\section{Developing a Composed Index of Critical Accessibility (CICA)}

Important factors used in analysing accessibility were the; population, number of villages, travel time used to reach the nearest road and finally distance covered. The factor values were combined together to compose an index of critical accessibility. The index comprised of total $\mathrm{Z}$ score values for all indicators used. $Z$ values are used because they explain how many standard deviations the individual scores are from mean (Hinton, 1999). Composed Index of Critical Accessibility was calculated in SIGEpi, the special program for health analysis by Pan Africa Health Organisation (Martinez et al., 2001). The CICA index was composed as Eq.2, Eq. 3.

$C I C A_{j}=\sum Z n_{i}=1$

Where; CICA = composed Index of Critical Accessibility, $\mathrm{i}=$ indicators, $\mathrm{j}=$ villages in each sub locations, $Z=Z$ score

Table.5: Travel time computed for major modes of transport used by households

\begin{tabular}{llll}
\hline Mobility & $\begin{array}{l}\text { Mean_Travel } \\
\text { Time }\end{array}$ & $\begin{array}{l}\text { Maximum_Travel } \\
\text { Time }\end{array}$ & $\begin{array}{l}\text { Average } \\
\text { Speed }\end{array}$ \\
\hline $\begin{array}{l}\text { Walking } \\
\text { Motor } \\
\text { cycle }\end{array}$ & $\begin{array}{l}\text { 18.7 Minutes } \\
\text { 3.9 Minutes }\end{array}$ & $\begin{array}{l}\text { 4hours.39 Minutes } \\
54.9 \text { Minutes }\end{array}$ & $\begin{array}{l}5 \mathrm{Km} / \mathrm{hr} \\
24 \mathrm{Km} / \mathrm{hr}\end{array}$ \\
Vehicle & 1.8 Minutes & 26.4 Minutes & $50 \mathrm{Km} / \mathrm{hr}$ \\
\hline
\end{tabular}

$Z=(X-\bar{x}) / S D$

Where:

$S D=$ Standard deviation, $X=$ Indicator value for villages, $\bar{x}$ $=$ Mean

CICA was generated for each sub location which contains aggregated population at village level for all households. In order to identify population exposed to the risk of inaccessibility, computed CICA was then classified and arranged into categories showing Very High risk, High risk, Medium risk, Low risk and Very Low risks of accessibility problems.

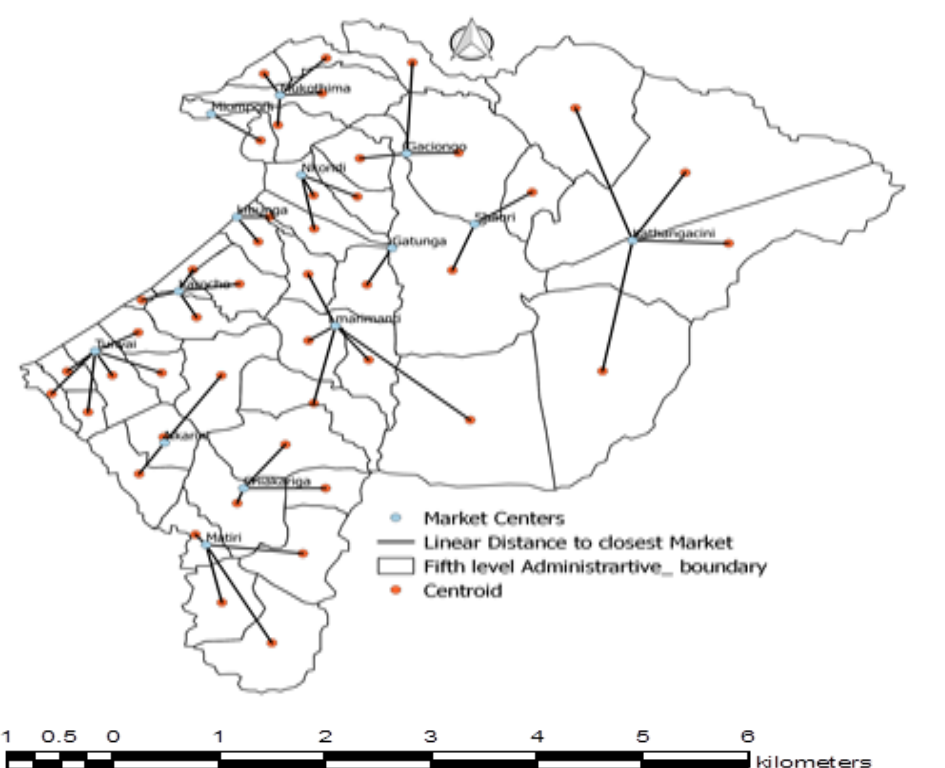

Figure 5: Straight-line Distance segments between each sub-location and its closest market centre. 


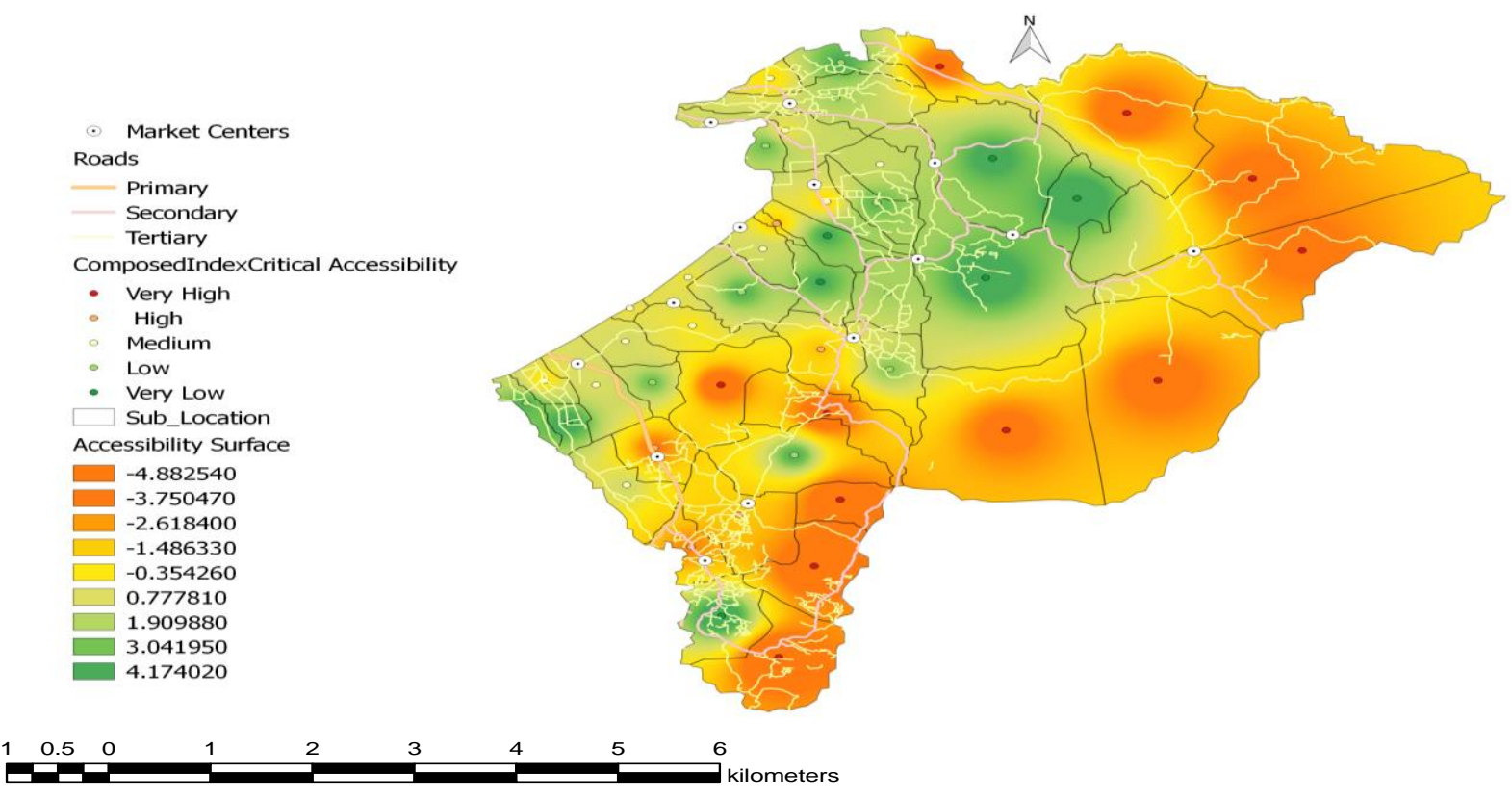

Figure 6: Village to market accessibility surface for households based on Composed Index of Critical Accessibility

\section{Creation of Accessibility Surface}

In order to spatially delineate and visualise areas of critical accessibility, boundary of possible accessibility surface was created. This was done through spatial interpolation of the composed index of critical accessibility $\mathrm{Z}$ values using Inverse Distance Weight (IDW). Inverse Distance Weight approach was used because it works on the premises that each input point has a local influence that diminishes as distance increases away from that point. From the generated market-village accessibility surface, areas with low accessibility to markets are shown in orange colour while those with high accessibility to markets are shown in green colour (Figure 6).

\section{RESULTS AND DISCUSSION}

\section{Population with access based on distances}

Population with access to each market facility at each of the 6-point equal interval distance scale is shown in Table 6. Straight line distance analysis revealed that 27,415 persons lived within half a kilometre to two and half kilometres from a market centre. 54,443people were found within a distance rang of two and half and four kilometres. Within four kilometres and six kilometres distance from a market, a total of 35,562 people were found living in this range. Only 19,761 people lived within six kilometres and eight kilometres distance. Minimal population of 1,780 persons lived between eight kilometres and ten kilometres from any given market centre. The population which lived over ten kilometres from any market was estimated at 11,049 persons.

Using six kilometres from a village centroid to the nearest market centre as maximum distance households were willing to travel to any market centre $80 \%$ of the population in semi-arid Tharaka live within a distance of $6 \mathrm{~km}$ to the nearest market centre. The mean distance of access to markets in the region was computed as 2.3 kilometres. In general, overall spatial concentration and distribution of population reached peak at 2.4 kilometres and 4.2 kilometres respectively.

Table.6: Population with access to each market for a 6point distance scale

\begin{tabular}{llr}
$\begin{array}{l}\text { Point } \\
\text { Distance range } \\
(\mathrm{Km})\end{array}$ & $\begin{array}{l}\text { Persons with } \\
\text { Access }\end{array}$ \\
\hline 1 & $0.5-2.4$ & 27,415 \\
2 & $2.4-4.2$ & 54,443 \\
3 & $4.2-6.1$ & 35,562 \\
4 & $6.1-8.0$ & 19,761 \\
5 & $8.0-9.8$ & 1,780 \\
6 & $9.8-11.7$ & 11,049 \\
\hline \multicolumn{2}{l}{ Source: own calculation }
\end{tabular}

Spatial distribution of village markets accessibility risks From the analysis, about $39.1 \%$ of the population live in areas with high accessibility risks while $22.7 \%$ are in medium risk zones and $38.2 \%$ of the population are found in low risk areas (Table 7).

Table.7: Spatial distribution of physical accessibility risks from villages to food market centres

\begin{tabular}{llllr}
$\begin{array}{l}\text { Composed } \\
\begin{array}{l}\text { Index of } \\
\text { Critical }\end{array}\end{array}$ & $\begin{array}{l}\text { Total_ } \\
\text { Population }\end{array}$ & $\begin{array}{l}\text { Number } \\
\text { of } \\
\text { Villages }\end{array}$ & $\begin{array}{l}\text { Average_ } \\
\text { Distance to } \\
\text { nearest } \\
\text { road (Km) }\end{array}$ & $\begin{array}{l}\text { Travel_ } \\
\text { Time } \\
\text { (Minutes) }\end{array}$ \\
\hline Very High & & 255 & 4.43 & 14.75 \\
High & 33,595 & 255 & 3.77 & 12.55 \\
Medium & 25,351 & 113 & 2.77 & 9.22 \\
Low & 34,325 & 159 & 1.01 & 3.32 \\
Very Low & 31,888 & 181 & 0.88 & 0.43 \\
\hline
\end{tabular}

Source: own calculation

This means 33,595 people live in villages with the highest risk of inaccessibility conditions, 25,351 persons in high risk places, 34,325 persons in moderate risk zones 
and 31,888 people in areas with low risk of poor accessibility. Villages with lowest risks of accessibility problems cover 20,755 persons geographically spread across the study area. A total of 368 villages across the five wards were found in sub locations with very high to high risks of accessibility. For instance, 255 villages had very high risks while 113 villages had high risks of accessibility respectively. About 159 villages were found in areas with moderate accessibility risks while 356 villages exist in low to very low accessibility risk areas.

Similarly, people within very high accessibility risk travel on average $4.4 \mathrm{~km}$ to the nearest road using about 15 minutes. Those in high accessibility risk areas cover about $3.8 \mathrm{~km}$ to reach a road from the village spending 13 minutes. In medium risk zones, people travel about $2.8 \mathrm{~km}$ to the nearest road within 9 minutes while those in low risk areas cover about one kilometre within 3 minutes. People living in very low accessibility areas travel about 900 meters to a road spending less 0.4 minutes.

\section{Areas of critical accessibility mapped}

Households identified to have low accessibility to markets are those found in the sub locations of Kathangacini, Mauthini, Twanthanju, Kamaguna, Kamwathu, Kirukuma, Kamanyaki, Uturini, Gituma, Rukenya, Nkarini, Matiri and Ntoroni respectively. These areas are not well served with roads and exist on the border with counties of Kitui to the East and South East and Meru County to the North and North East. Additionally, household within Gatunga, Kanjoro, Irunduni, Marimanti, Rukurini, Ibote, Tubui, Gakirwe, Kaguma, Kamarandi, Tumbora, Kirundi, Mukothima, Kithigiri, Kamatungu and Mwerera sub locations fall in areas with high accessibility. These areas are well served by many feeder roads and the only major secondary trunk road connecting Embu, Kitui and Meru Counties with Tharaka Nithi county passes through these areas.

\section{CONCLUSIONS}

In an attempt to analyse challenges of physical accessibility to markets by locals in Tharaka constituency, two extremes were considered with location of people on one hand and market availability on the other. Populated places aggregated at sub location level were geocoded by a centroid through assigning population data to that geometry. Location coordinates of open air markets was collected in the field using a GPS receiver while road network and associated data was acquired from relevant authorities. Travel time and distances were considered important indicators of physical accessibility in this case study.

When distance was analysed across the study area, $59 \%$ of the population lived within 2.5 kilometres to 6 kilometres from nearest market with $18 \%$ within less than 2.5 kilometres and about $23 \%$ of the total population living over 6 kilometres from the closest market centre. As per travel time computed for both motorised and nonmotorised mobility, folks walking to the nearest road from their homesteads would use on average 18.7 minutes if walking at a speed of $5 \mathrm{~km} / \mathrm{hr}$. Those using motor cycles would use only 3.9 minutes riding at a mean speed of
$24 \mathrm{~km} / \mathrm{hr}$ while those opting for vehicular movement would use 1.8 minutes driving at an average speed of $50 \mathrm{~km} / \mathrm{hr}$. On the basis of accessibility, 52,643 people living in 356 geographically dispersed villages are found in areas with low accessibility, while 34,325 people within 159 villages live in areas with moderate ease of accessibility. A total of 58,946 people spread across 368 villages live in areas with high accessibility. These are opened up regions with improved roads and more transportation alternatives to reach market centres.

This study has succeeded in showing approaches that can be used to establish conditions of physical accessibility to village food markets for populated rural areas. Additionally, markets within areas having higher risks of inaccessibility were identified as Kathangacini, Chiakariga, Matiri and Nkarini market centres. These market facilities should be considered by the county government of Tharaka Nithi for upgrading in order to address local food needs. Furthermore, identified areas of very high to high inaccessibility risks represent "food deserts" which can be targeted by county government for relief food distribution and construction of village feeder roads to link households to market centres.

There is need to lower food prices and market usage fees across all markets in an effort to promote increased supply and consumption of locally produced foods. It is important to have sections within open air markets where local farmers can sell their produce and get a chance to interact with consumers. Similarly, public health and sanitation of food markets through provision of clean tap water, waste bins and toilets should be a priority for authorities to ensure markets hygiene and food safety is realised. Further research should be done to investigate patronage behaviour of market users as well as spatial availability of market services in the country if the food availability and access pillar of Kenya's Food and Nutrition Security Policy is to be strengthened.

\section{REFERENCES}

ASFAW. S., SHIFERAW, B., SIMTOWE, F., MURICHO, G., ABATE, T., \& FEREDE, S. (2010). Socio-economic Assessment of Legume Production, Farmer Technology Choice, Market Linkages, Institutions and Poverty in Rural Ethiopia: Institutions, Markets, Policy and Impacts Research Report No. 3. International Crops Research Institute for the Semi-Arid Tropics, Nairobi, Kenya. http://oar.icrisat.org/3266/

BHATTI, M. A. (2005). Geographical patterns of access and utilization of basic health unit in District Attock. Journal of Liaquat University of Medical and Health Sciences, 4(2), 48-53. DOI: 10.22442/jlumhs.05420058 EYZAGUIRRE, P., GRUM, M., MAUNDU, P., VODOUHE, S. R., JOHNS, T., ONIANGO, R., KAKURAMATSI-KIKAFUNDA, J., NDOSSI, G. D., \& GUIRO, A. T. (2006). Dietary Diversity: Linking Traditional Food and Plant Genetic Resources to Rural and Urban Health in Sub-Saharan Africa; Technical Report; Via dei Tre Denari 472/a 00057; Bioversity International: Maccarese, Italy: pp. 1-36.

GOK. GOVERNMENT OF KENYA (2011). National Food and Nutrition Security Policy. 
HINTON, G. E. (1999). Supervised learning in multilayer neural networks in The MIT Encyclopaedia of the Cognitive Sciences Editors: Robert A. Wilson and Frank C. Keil. The Michigan Institute of Technology Press.

ISS. INTEGRATED SMART SURVEY (2016). SMART Tharaka Nithi County Emergency Nutrition Assessment Report, Kenya for September 2016

JAYNE, T. S., CHAMBERLIN, J., TRAUB, L., SITKO, N., MUYANGA, M., YEBOAH, F. K., ANSEEUW, W., CHAPOTO, A., WINEMAN, A., NKONDE, CH., \& KACHULE, R. (2016). Africa's changing farm size distribution patterns: the rise of medium-scale farms. Agricultural Economics, 47(1), 197-214. DOI: $\underline{10.1111 / \text { agec. } 12308}$

KAYODE, J. S., \& EFOSA, A. (2014). A composed index of critical accessibility (CICA) to healthcare services in a traditional African City. GeoJournal, 3(79), 267-278. DOI: $10.1007 / \mathrm{s} 10708-013-9485-\mathrm{y}$

KNBS. KENYA NATIONAL BUREAU OF STATISTICS (2009). Tharaka District Multiple Indicator Cluster Survey 2008

MAKHURA, M. T. (2001). Overcoming transaction costs barriers to market participation of smallholder farmers in the Northern Province of South Africa. Unpublished PhD thesis. University of Pretoria, Pretoria, South Africa MARTINEZ, R., VIDAURRE, M., NAJERA, P., LOYOLA, E., CASTILLO-SALGADO, C., \& EISNER, C. (2001). SIGEpi: Geographic Information System in Epidemiology and Public Health. PAHO. Epidemiological bulletin, 22(3), 4-5.

NELSON, A (2000). Accessibility, Transport and Travel Time Information. International Center for Tropical Agriculture (CIAT), Hillsides Project Report.

NOOR, A. M., AMIN, A. A., GETHING, P. W., ATKINSON, P. M., HAY, S. I., \& SNOW, R. W. (2006). Modelling distances travelled to government health services in Kenya. Tropical Medicine \& International Health, 11(2), 188-196. DOI: 10.1111/j.13653156.2005.01555.x

OUKO, J. J. O., GACHARI, M. K., SICHANGI, A. W., \& ALEGANA, V. (2019). Geographic Information System-based evaluation of spatial accessibility to maternal health facilities in Siaya County, Kenya. Geographic Research: 1-13. DOI: 10.1111/1745$\underline{5871.12339}$

OMITI, J. M., OTIENO, D. J., NYANAMBA, T. O., \& MCCULLOUGH, E. B. (2009). Factors influencing the intensity of market participation by smallholder farmers: A case study of rural and peri-urban areas of Kenya. African Journal of Agricultural Resource Economics, 3(1), 57-82. DOI: 10.22004/ag.econ.56958

RAY, N., \& EBENER, S. (2008). AccessMod 3.0: computing geographic coverage and accessibility to health care services using anisotropic movement of patients. International Journal of Health Geographics, 7:63. DOI: https://doi.org/10.1186/1476-072X-7-63

RSA. RESEARCH SOLUTIONS AFRICA (2015). Report of a study on fresh vegetables market in Kenya desk review. Retrieved from http://www.researchsolutionsafrica.com

SMOYER-TOMIC, K. E., HEWKO, J. N., \& HODGSON, M. J. (2004). Spatial accessibility and equity of playgrounds in Edmonton Canada, The Canadian Geographer,48(3),287-302. DOI: $10.1111 / \mathrm{j} .0008-$ 3658.2004.00061.x

SMUCKER. T. A., \& WISNER, B. (2008). Changing household responses to drought in Tharaka, Kenya: vulnerability, persistence and challenge. Blackwell Publishing, USA. pp. 190-215. DOI: $10.1111 / \mathrm{j} .1467-$ 7717.2007.01035.x

TOBLER, W. (1993). Three Presentations on Geographical Analysis and Modeling: National Center for Geographic Information and Analysis Technical Report no 93-1. University of California, Santa Barbara

TORERO, M. (2011). A framework for Linking Small Farmers to Markets. Presented at the IFAD Conference on New Directions for Smallholder Agriculture, Rome, Italy. $41 \mathrm{pp}$.

WAITHAKA, M. M., THORNTON, P. K., HERRERO, M., \& SHEPHERD, K. D. (2006). Bio-economic evaluation of farmers' perceptions of viable farms in western Kenya. Agricultural Systems, 90(1-3), 243-27. DOI: $10.1016 /$ j.agsy.2005.12.007

WFP. United Nations World Food Programme. (2006). Comprehensive Food Security and Vulnerability Analysis: An External Review of WFP Guidance and Practice. Rome, Italy. 112 pp. Retrieved from https://documents.wfp.org/stellent/groups/public/docume nts/ena/wfp103646.pdf

WRS. WORLD RESOURCES INSTITUTE (2019). Global road datasets shape files. Survey of Kenya (SOK), Japan International Cooperation Agency (JICA) and International Livestock Research Institute (ILRI). 1996. Digital Elevation Model created by ILRI and JICA, derived from SoK 1:250,000 Topographic Map. Retrieved from http://www.wri.org./Kenya-roads-shapefile.html 